\title{
EFEITO CRIOPROTETOR DE DIFERENTES CONCENTRAÇÕES DO DIMETILSULFÓXIDO NO CONGELAMENTO DE SÊMEN DE TAMBAQUI Colossoma macropomum
}

\author{
ANTONIO SERGIO VARELA JUNIOR ${ }^{1,2}$; CARINE DAHL CORCINI ${ }^{1}$, DANILO PEDRO STREIT JR. ${ }^{3}$, GUILHERME RIZZOTO $^{1}$, RODRIGO $^{3}$ \\ DESSESARDS JARDIM ${ }^{2}$, THOMAZ LUCIA JR. ${ }^{3}$, MARIO ROBERTO CHIM FIGUEIREDO ${ }^{1}$ \\ ${ }^{1}$ Universidade Federal do Rio Grande - Instituto de Oceanografia, estação Marinha de Aquacultura, Rua do Hotel 2, Cassino, \\ Rio Grande - RS - Brasil. CEP: 96210-030 - antoniovarela@furg.br \\ ${ }^{2}$ Universidade Federal do Rio Grande - Instituto de Ciências Biológicas - Av. Itália km-8, Rio Grande - RS - Brasil. CEP: $96201-900$ \\ ${ }^{3}$ Universidade Federal de Pelotas, Faculdade de Veterinária, 96010-900, Pelotas, RS, Brasil
}

\section{RESUMO}

O objetivo deste trabalho foi avaliar o efeito do diluente com dimetilsulfóxido (DMSO) sobre a estrutura e funcionalidade do espermatozóide de tambaqui Colossoma macropomum criopreservado. O sêmen foi diluído 1/9 (v/v) em Beltsville Thawing Solution acrescido de $5,10,15$ e $20 \%$ de DMSO. Após dois minutos foi congelado em botijão dry shipper $\left(-76^{\circ} \mathrm{C} / 12 \mathrm{~h}\right)$, sendo armazenado em botijão de NL $\left(-196^{\circ} \mathrm{C}\right)$. Após 15 dias o sêmen criopreservado foi avaliado quanto às taxas de motilidade, latência, fertilização, eclosão, integridade de membrana e de DNA, funcionalidade mitocondrial e viabilidade. As taxas de fertilização e eclosão com 10\% DMSO não diferiram $(P>0,05)$ do sêmen fresco. Os diluentes com 5 e $10 \%$ de DMSO foram superiores $(P<0,05)$, nas avaliações de motilidade, latência e integridade de DNA do espermatozóide, às concentrações $15 \mathrm{e}$ $20 \%$. Entretanto, a viabilidade celular nas concentrações 5 e $10 \%$ de DMSO foi inferior $(P<0,05)$ à obtida com $20 \%$ de DMSO, enquanto com $15 \%$ de DMSO não diferiu $(P>0,05)$ das demais concentrações. Considerando os resultados in vivo e in vitro, nas condições experimentais relatadas, o DMSO na concentração de $10 \%$ foi associado à melhor manutenção da qualidade de sêmen criopreservado de Tambaqui.

PALAVRAS CHAVE: Esperma, migrador, criopreservação, peixe

\section{ABSTRACT}

Effect of dimethylsulfoxide on the quality of post-thaw sperm of Tambaqui, Colossoma macropomum

The objective of this study was to evaluate the effect of an extender including dimethylsulfoxide (DMSO) on the structure and functionality of frozen sperm of tambaqui Colossoma macropomum. Sperm was extended $1 / 9(\mathrm{v} / \mathrm{v})$ in Beltsville Thawing Solution including $5 \%, 10 \%, 15 \%$ and $20 \%$ DMSO. After two minutes, sperm was frozen in dry shipper $\left(-76{ }^{\circ} \mathrm{C} / 12 \mathrm{~h}\right)$ and subsequently stored in liquid nitrogen $\left(-196^{\circ} \mathrm{C}\right)$. After 15 days, sperm was evaluated according to: motility; latency period; fertilization and hatching rates; membrane and DNA integrity; mitochondrial functionality, and viability. Fertilization and hatching rates with 10\% DMSO did not differ from those with fresh sperm $(P>0.05)$. Extenders including $5 \%$ and $10 \%$ DMSO presented greater $(P<0.05)$ sperm motility, latency period and DNA integrity than extenders including $15 \%$ and $20 \%$ DMSO. However, sperm viability with $5 \%$ and $10 \%$ DMSO was lower $(P<0.05)$ than with $20 \%$ DMSO, but for the extender with $15 \%$ DMSO, sperm viability was similar to that with other concentrations $(P>0.05)$. Considering those results, the extender with $10 \%$ DMSO was associated with improved quality of frozen sperm of Tambaqui.

KEYWORDS: Sperm, migratory, cryopreservation, fish.

\section{INTRODUÇÃO}

O tambaqui Colossoma macropomum é a espécie nativa brasileira mais produzida comercialmente (FAO 2008), sendo um peixe de fácil manuseio e rápido crescimento (Chellapa et al. 1995, Maria et al. 2011). Entretanto, por ser uma espécie reofílica (Froese \& Pauly 2009), sua reprodução em cativeiro depende de realização de indução hormonal e posterior fertilização artificial.

A fertilização artificial pode ser aplicada para aumentar a produção, atendendo à grande demanda e diminuindo a exploração dos recursos naturais. A criopreservação é uma técnica valiosa no melhoramento genético em planteis (Suquet et al. 2000), além de proporcionar um contínuo fornecimento de sêmen de boa qualidade para a fertilização artificial. Para o sucesso do congelamento é necessário que os diluentes utilizados na preservação seminal tenham $\mathrm{pH}$ e osmolalidade adequados, boa capacidade de tamponamento e proteção da lesão criogênica (Salamon \& Maxwell 2000). A composição dos diluentes, concentração dos crioprotetores e método de congelamento podem afetar a qualidade final do sêmen (Sansone et al. 2002, DeGraaf \& Berlinsky 2004). Os crioprotetores internos minimizam as perdas da qualidade espermática, agindo diretamente sobre as organelas e funcionalidades espermáticas (Holt 2000). As ações destas substâncias crioprotetoras são evitar danos na membrana espermática (Hu et al. 2009), prevenir a desnaturação do DNA (Hu et al. 2008, Koderle et al. 2009) e evitar lesões nas mitocôndrias e microtúbulos (Hammerstedt \& Graham 1992). Vários crioprotetores internos tem sido testados em peixes brasileiros, sendo o dimetilsulfóxido (DMSO), nas concentrações de $5-15 \%$, o mais efetivo na crioproteção aos espermatozóides (Viveiros \& Godinho 2009).

Segundo Menezes et al. (2008), utilizando os crioprotetores etilenoglicol, dimetilsulfóxido, propilenoglicol, dimetilacetamida e metanol (concentrações e diluente base não descritos), a 
motilidade pós-descongelamento do sêmen de tambaqui variou entre 5 e $20 \%$. Farias \& Nunes (1999), que utilizaram água de coco e $5 \%$ de glicerol como diluidores de congelamento do sêmen de tambaqui, observaram uma variação na motilidade espermática pós-descongelamento entre 30 e $80 \%$. Porém, nesses estudos, não foi verificada a ação das diferentes concentrações de um mesmo crioprotetor, nem a ação destes sobre a viabilidade e as estruturas (membrana, mitocôndria e DNA) das células espermáticas descongeladas.

Em decorrência destes fatos, o presente estudo teve como objetivo avaliar o efeito das diferentes concentrações de DMSO sobre as estruturas (mitocôndrias, membranas celulares e DNA) e sobre a funcionalidade (motilidade, tempo de latência, viabilidade, taxa de fertilização e taxa de eclosão) de células espermáticas criopreservadas de Colossoma macropomum.

\section{MATERIAIS E MÉTODOS}

O trabalho de coleta foi realizado no período de novembro de 2009 a fevereiro de 2010, na Piscicultura Boa Esperança, em Pimenta Bueno, Rondônia. As análises da qualidade seminal foram realizadas no Laboratório de Biotecnologia em Reprodução Animal da Universidade Federal de Pelotas (UFPel) e no Laboratório de Histologia da Universidade Federal de Rio Grande (FURG), Rio Grande do Sul, Brasil. Todas as substâncias químicas utilizadas são provenientes da Sigma Chemical Company® (St. Louis, MO - USA).

\section{Peixes}

Avaliou-se o efeito do DMSO, durante a criopreservação seminal, sobre as células espermáticas de $C$. macropomum. Foram utilizados 8 machos e 4 fêmeas em idade reprodutiva ( 3 a 4 anos) no experimento. Os animais foram mantidos em viveiros, sob condições ambientais, sendo alimentados com ração comercial com $40 \%$ de proteína bruta e $2900 \mathrm{kcal}$ de energia metabolizável/kg de ração, com uma frequência alimentar de três vezes na semana, servindo-se $3 \%$ do peso vivo por vez.
Os machos foram despescados dos viveiros, sendo imediatamente induzidos com 1,0 mg de extrato de hipófise de carpa $/ \mathrm{kg}$, de animal vivo, diluído em 0,5 $\mathrm{mL}$ de soro fisiológico estéril $(0,9 \%$ de $\mathrm{NaCl})$, aplicado na região dorso lateral. Após, os peixes foram mantidos em dois tanques (3.000 L) de manipulação (no máximo quatro animais em cada), com coluna d'água de 70 centímetros, em fluxo constante sob temperatura de $28^{\circ} \mathrm{C}$, por no máximo 24 hs. Após $6 \mathrm{~h}$ e $15 \mathrm{~min}$ (175 horas-grau) foi realizada massagem abdominal, coletando-se o sêmen com tubo cônico de $15 \mathrm{~mL}$ (um para cada animal), registrando-se o volume coletado. Foi evitada a extrusão simultânea de fezes e/ou urina, a fim de não ativar os espermatozóides nem contaminar as amostras, como recomendado por Billard et al. (1995).

Antes da criopreservação, cada amostra seminal foi avaliada, por um único observador, quanto à motilidade e tempo de latência, descartando amostras que não apresentavam motilidade acima de $80 \%$ em $10 \mathrm{~s}$ após a ativação com água destilada. A motilidade (percentual de células móveis) foi avaliada colocandose 1,0 L de sêmen e 99,0 L de água destilada em lâmina sob lamínula, em microscópio óptico de contraste de fases (Maria et al. 2011). Para avaliar o tempo de latência, foi mensurado o tempo desde a ativação até a parada total da movimentação espermática (segundos). A concentração espermática foi determinada por meio de câmara de Neubauer, contando-se em microscópio óptico (Maria et al. 2011).

\section{Criopreservação Seminal}

A solução base para diluição foi o Beltsville Thawing Solution (BTS) constituído de $37,00 \mathrm{~g}$ de glicose; $6,00 \mathrm{~g}$ de citrato de sódio di-hidratado; $1,25 \mathrm{~g}$ de bicarbonato de sódio; $1,25 \mathrm{~g}$ de etilenodiamino tetracetato e $0,90 \mathrm{~g}$ de cloreto de potássio em 1,00 L de água destilada (Pursel \& Johnson 1975).

O sêmen de cada macho $(n=8)$ foi diluído $1 / 9$ $(\mathrm{v} / \mathrm{v})$ em todos os tratamentos (5, 10, 15 e 20\%) de DMSO em solução base (BTS). Para cada repetição (machos) de cada tratamento $(5,10,15$ e $20 \%$ de DMSO em BTS) foram envasadas 5 palhetas de 250 L, identificadas, colocadas em tubos plásticos e fixadas nas racks, permanecendo por cinco minutos a $24{ }^{\circ} \mathrm{C}$. Após, foram alocadas no canister de um botijão do tipo dry shipper (Taylor-Wharton, modelo

\section{Coleta e avaliação seminal}


CP 300 dry shipper), com vapor de nitrogênio, sendo congeladas de acordo com Taitson et al. (2008). As palhetas permaneceram por 12 horas no dry shipper, sendo finalmente transferidas para 0 botijão de nitrogênio líquido (MVE, modelo CP-34), onde ficaram estocadas por, no mínimo, 15 dias a $-196^{\circ} \mathrm{C}$.

\section{Descongelamento seminal e avaliações da taxa de fertilização e eclosão}

Para avaliar a taxa de fertilização foram utilizadas quatro fêmeas, uma para cada dois machos, ou seja, na desova de uma fêmea eram testados os quatro tratamentos de dois machos. As fêmeas foram induzidas à desova com extrato de hipófise de carpa $(5,0 \mathrm{mg} / \mathrm{kg}$ de peso corpóreo), diluído em 2,0 mL de soro fisiológico estéril $(0,9 \%$ de $\mathrm{NaCl})$, sendo aplicado com seringa de $2,0 \mathrm{~mL}(2 / 0,01$ $\mathrm{mL}$ ), na região dorso lateral. Os óvulos foram extrusados por massagem abdominal e coletados em Becker de $1000 \mathrm{~mL}$, sendo divididos em seis alíquotas de 2,0 g cada.

Alíquotas de $150 \mu \mathrm{L}$ de sêmen oriundos de cada macho, criopreservada com diferentes tratamentos foram descongeladas de acordo com Streit Jr et al. (2006), a $45^{\circ} \mathrm{C}$, por $5 \mathrm{~s}$, e fertilizaram as alíquotas de óvulos. As outras duas alíquotas de óvulos restantes de cada fêmea foram fertilizadas com $15 \mu \mathrm{L}$ sêmen fresco, coletado de dois machos no momento da execução do teste. As alíquotas de ovos fertilizados com sêmen fresco serviram de controle para assegurar a qualidade dos óvulos, descartandose as amostras com menos de $80 \%$ de taxa de fertilização. $O$ sêmen fresco foi utilizado para fertilizar a primeira e a última alíquota de óvulos.

$\mathrm{Na}$ execução dos testes de fertilização, as células espermáticas foram colocadas em contato com as alíquotas dos óvulos em becker de $20 \mathrm{~mL}$. A ativação do sêmen foi realizada mediante a adição, ao Becker com $2 \mathrm{~g}$ de óvulos, de $2,0 \mathrm{~mL}$ de água destilada na temperatura de $28^{\circ} \mathrm{C}$. Após, o material foi homogeneizado suavemente por aproximadamente $5 \mathrm{~s}$ e permaneceu em descanso por 2 minutos. Ao final deste período, foram adicionados $10,0 \mathrm{~mL}$ de água destilada em cada uma das alíquotas, visando hidratar os ovos fertilizados. Após foram incubados sob fluxo de água delicado e constante de $150 \mathrm{~mL} / \mathrm{min}$ em incubadoras experimentais de $2 \mathrm{~L}$.
O acompanhamento dos estágios de desenvolvimento embrionário foi realizado com uso de estereomicroscópio. A taxa de fertilização foi avaliada após 8 horas, sendo considerado o número de ovos fertilizados sobre o total de óvulos ( $2 \mathrm{~g}$ ) e ao final expresso em percentual. Já a taxa de eclosão foi avaliada considerando-se 0 total de embriões eclodidos, sobre o total de ovos fertilizados, sendo ao final expresso em percentual.

\section{Funcionalidade mitocondrial, viabilidade, integridade de membrana e DNA}

As amostras foram descongeladas a $45^{\circ} \mathrm{C}$ durante $5 \mathrm{~s}$ (Streit Jr et al. 2006), sendo re-suspensas em $400 \mu \mathrm{L}$ de BTS $(1: 3, v / v)$, à temperatura de $22^{\circ} \mathrm{C}$, em tubo cônico de $1,5 \mathrm{~mL}$, sendo posteriormente analisada a motilidade espermática, tempo de latência, funcionalidade mitocondrial, viabilidade celular, integridade de membrana e DNA.

As avaliações de motilidade espermática e de tempo de latência foram realizadas conforme descrito para o sêmen fresco. A funcionalidade mitocondrial foi avaliada com a utilização da coloração fluorescente rhodamina 123 (He \& Woods 2004). A viabilidade celular foi avaliada com os corantes histoquímicos eosina e nigrosina (Maria et al. 2011). A integridade de membrana dos espermatozóides foi avaliada com uso de sondas fluorescentes de diacetato de carboxifluoresceína - CFDA e iodeto de propídio - PI (Harrison \& Vickers 1990). A integridade do DNA foi avaliada por meio da sonda acridine orange (Bencharif et al. 2010). As avaliações de funcionalidade mitoccondrial, integridade de membrana e de DNA foram realizadas em microscópio de epifluorescência (Olympus ${ }^{\circledR}$ BX 51, América INC, São Paulo - Brasil), com 5 L de solução com espermatozóides em lâmina sob lamínula ( $18 \times 18 \mathrm{~mm}$ ), avaliando-se 200 células por amostra. As taxas foram expressas através do percentual entre células íntegras/funcionais sobre o total de células avaliadas.

\section{Análise Estatística}

Foi realizada análise de variância de KruskalWalis para medidas não paramétricas, com posterior comparação Post Hoc entre os tratamentos. As diferentes concentrações de DMSO foram consideradas variáveis independentes, e as taxas de 
ANTONIO SERGIO VARELA JUNIOR; CARINE DAHL CORCINI, DANILO PEDRO STREIT JR., GUILHERME RIZZOTO, RODRIGO DESSESARDS JARDIM, THOMAZ LUCIA JR., MARIO ROBERTO CHIM FIGUEIREDO

fertilização e eclosão, motilidade espermática, tempo de latência, funcionalidade mitocondrial, viabilidade celular, e integridade de membrana e DNA, foram consideradas variáveis dependentes. Para fins de interpretação, os dados foram expressos em média \pm erro padrão da média. As correlações, dentre as variáveis, foram realizadas através do teste de Spearman. Todas as análises foram realizadas no software Statistix 9.0 (2008).

\section{RESULTADOS}

Os machos utilizados no experimento produziram em média $8,6 \pm 0,4 \mathrm{~mL}$ de volume de

TABELA 1 - Taxas de fertilização e de eclosão (média \pm erro padrão da média) obtidas com sêmen de $C$. macropomum fresco e descongelado, após congelamento com diferentes concentrações de dimetilsulfóxido (DMSO)

\begin{tabular}{lcc}
\hline Diluentes & Taxa de Fertilização (\%) & Taxa de Eclosão (\%) \\
\hline Sêmen fresco & $86,8 \pm 2,0^{\mathrm{a}}$ & $79,9 \pm 1,7^{\mathrm{a}}$ \\
$5 \%$ DMSO & $39,8 \pm 3,6^{\mathrm{bc}}$ & $37,4 \pm 4,5^{\mathrm{b}}$ \\
$10 \%$ DMSO & $60,3 \pm 2,2^{\mathrm{ab}}$ & $47,3 \pm 2,5^{\mathrm{ab}}$ \\
$15 \%$ DMSO & $26,0 \pm 3,8^{\mathrm{bc}}$ & $18,5 \pm 3,4^{\mathrm{bc}}$ \\
$20 \%$ DMSO & $5,4 \pm 1,2^{\mathrm{c}}$ & $2,4 \pm 1,4^{\mathrm{c}}$
\end{tabular}

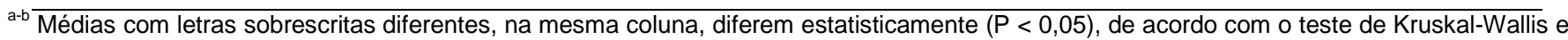
comparação com Post Hoc entre os tratamentos.

As variáveis motilidade, tempo de latência e integridade de DNA dos espermatozóides, utilizando os diluentes com 5 e 10\% de DMSO foram superiores $(P<0,05)$ aos resultados obtidos nas concentrações 15 e $20 \%$ de DMSO (Tabelas 2 e 3). Entretanto, a viabilidade celular dos tratamentos com a adição de 5 e 10\% de DMSO foi inferior $(P<0,05)$ à obtida no tratamento com $20 \%$ de DMSO, enquanto no tratamento com $15 \%$ de DMSO não diferiu $(P>0,05)$ de nenhum outro tratamento (Tabela 2$)$.

TABELA 2 - Taxas de motilidade, tempo de latência e viabilidade espermática (média \pm erro padrão da média) obtidas com sêmen de C. macropomum descongelado, após congelamento com diferentes concentrações dimetilsulfóxido (DMSO)

\begin{tabular}{llll}
\hline Diluentes & Taxa de Motilidade (\%) & Tempo de Latência (s) & Viabilidade Celular (\%) \\
\hline $5 \%$ DMSO & $19,0 \pm 2,6^{\mathrm{a}}$ & $21,3 \pm 2,3^{\mathrm{a}}$ & $49,4 \pm 1,9^{\mathrm{b}}$ \\
$10 \%$ DMSO & $20,0 \pm 2,5^{\mathrm{a}}$ & $29,7 \pm 2,7^{\mathrm{a}}$ & $48,7 \pm 2,8^{\mathrm{b}}$ \\
$15 \%$ DMSO & $0,0 \pm 0,0^{\mathrm{b}}$ & $0,0 \pm 0,0^{\mathrm{b}}$ & $53,4 \pm 3,1^{\mathrm{ab}}$ \\
$20 \%$ DMSO & $0,0 \pm 0,0^{\mathrm{b}}$ & $0,0 \pm 0,0^{\mathrm{b}}$ & $60,8 \pm 2,6^{\mathrm{a}}$ \\
\hline
\end{tabular}

${ }^{a-b}$ Médias com letras sobrescritas diferentes, na mesma coluna, diferem estatisticamente $(P<0,05)$, de acordo com o teste de Kruskal-Wallis e comparação com Post Hoc entre os tratamentos.

Quanto à integridade de membrana, os tratamentos com 10, 15 e $20 \%$ de DMSO não diferiram $(P<0,05)$ entre si, porém o tratamento com $5 \%$ de DMSO foi inferior $(P<0,05)$ aos tratamentos 
com 15 e 20\% de DMSO (Tabela 3). Já para a funcionalidade mitocondrial não houve diferença $(P>$ $0,05)$ entre as concentrações de DMSO utilizadas na criopreservação espermática (Tabela 3). Houve correlações significativas $(P<0,05)$ entre as diferentes concentrações do crioprotetor com as variáveis dependentes motilidade espermática $(r=-$ $0,82)$, tempo de latência $(r=-0,83)$, integridade de DNA $(r=-0,83)$, viabilidade celular $(r=0,50)$, integridade de membrana $(r=0,65)$ e funcionalidade mitocondrial $(r=0,36)$.

TABELA 3 - Taxas de integridade de membrana, integridade do DNA e funcionalidade da mitocôndria (média \pm erro padrão da média) obtidas com sêmen de $C$. macropomum descongelado, após congelamento com diferentes concentrações de dimetilsulfóxido (DMSO)

\begin{tabular}{llll}
\hline Diluentes & Integridade de Membrana (\%) & Integridade do DNA (\%) & Funcionalidade da Mitocôndria (\%) \\
\hline $5 \%$ DMSO & $19,8 \pm 2,0^{\mathrm{b}}$ & $71,8 \pm 4,0^{\mathrm{a}}$ & $26,0 \pm 2,3^{\mathrm{a}}$ \\
$10 \%$ DMSO & $23,9 \pm 2,1^{\text {ab }}$ & $48,2 \pm 2,8^{\mathrm{a}}$ & $29,5 \pm 2,2^{\mathrm{a}}$ \\
$15 \%$ DMSO & $30,8 \pm 1,4^{\mathrm{a}}$ & $19,4 \pm 1,9^{\mathrm{b}}$ & $36,2 \pm 4,1^{\mathrm{a}}$ \\
$20 \%$ DMSO & $32,1 \pm 1,7^{\mathrm{a}}$ & $24,1 \pm 3,2^{\mathrm{b}}$ & $36,6 \pm 4,3^{\mathrm{a}}$
\end{tabular}

a-b Médias com letras sobrescritas diferentes, na mesma coluna, diferem estatisticamente $(P<0,05)$, de acordo com o teste de Kruskal-Wallis e comparação com Post Hoc entre os tratamentos.

\section{DISCUSSÃO}

Em várias espécies de peixes nativos brasileiros, Brycon amazonicus (Cruz-Casallas et al. 2004, Velasco-Santamaria et al. 2006), B. orthotaenia (Melo \& Godinho 2006), Leporinus obtusidens (Taitson et al. 2008) Salminus brasiliensis (Coser et al. 1984, Carolsfeld et al. 2003) Prochilodus lineatus (Carolsfeld et al. 2003, Felizardo et al. 2010) B. orbignyanus, L. elongatu e Piaractus mesopotamicus (Carolsfeld et al. 2003), o DMSO foi utilizado com sucesso no congelamento seminal. No presente estudo foram observados resultados similares, pois na concentração de $10 \%$ de DMSO obtiveram-se os melhores resultados nas avaliações de motilidade, tempo de latência e integridade de DNA dos espermatozóides, e nas taxas de fertilização e de eclosão. Deve ser ressaltado que não houve diferença, nas taxas de fertilização e eclosão, entre o sêmen fresco e o sêmen criopeservado com $10 \%$ de DMSO.

Observou-se que os espermatozóides perderam qualidade devido a toxidez da solução crioprotetora e a exposição à baixa temperatura, promovendo a queda da motilidade no sêmen fresco para valores não superiores a $20 \%$. Um indicativo desta combinação de fatores pode ser deduzido a partir dos resultados da funcionalidade mitocondrial, integridade de membrana e DNA, obtidos com as diferentes concentrações utilizadas de DMSO. As concentrações mais baixas mantiveram melhor a integridade de DNA, apresentando correlação negativa $(-0,83)$ e significativa $(P<0,05)$ com as concentrações deste crioprotetor, demonstrando sua toxidez em relação ao material genético do espermatozóide. Já as altas concentrações diminuíram o rompimento das membranas, pois minimizam a formação de cristais de gelo e promovem a desidratação espermática (He \& Woods 2004), melhorando assim a integridade de membrana e mitocôndria, e apresentaram correlações positivas $(0,66$ e 0,36 , respectivamente) e significativas $(P<$ $0,05)$ com a concentração do crioprotetor. Deste modo, a concentração de crioprotetor que produziu melhor combinação entre menor toxidez e maior proteção no congelamento do espermatozóide de $C$. macropomum foi de $10 \%$.

$\mathrm{Na}$ criopreservação de B. amazonicus, CruzCasallas et al. (2004) obtiveram, com 10\% de DMSO, as melhores taxas de motilidade $(68,8 \%)$ e de fertilização, que foram de 31,51 e $58 \%$ para 114.285 , 228.571 e 457.142 espermatozóides por ovo (respectivamente), sendo que os autores utilizaram quantidade de espermatozóides muito superior ao utilizado no presente trabalho (30.416 espermatozóides por ovo). No estudo com $L$. 
ANTONIO SERGIO VARELA JUNIOR; CARINE DAHL CORCINI, DANILO PEDRO STREIT JR., GUILHERME RIZZOTO, RODRIGO DESSESARDS JARDIM, THOMAZ LUCIA JR., MARIO ROBERTO CHIM FIGUEIREDO

obtusidens, a taxa de fertilização com sêmen criopreservado variou também de acordo com o número de espermatozóides (móveis) utilizados, obtendo taxa de fertilização de $74,58,37$ e $22 \%$ com 112.456, 84.343, 56.228 e 28.114 espermatozóides móveis por ovo, respectivamente (Taitson et al. 2008). Esses resultados comprovam que a fertilização $(60,3 \%)$ encontrada no presente trabalho, com $10 \%$ de DMSO diluído em BTS, está relativamente alta, considerando o baixo número de espermatozóides móveis utilizados (6.083 espermatozóides móveis por ovo).

A toxidez do DMSO nas concentrações de $15 \mathrm{e}$ $20 \%$ resultou em motilidade e tempo de latência nulos, entretanto, ocorreu fertilização e eclosão. Isto pode estar relacionado à elevada concentração espermática das espécies reofílicas e/ou em razão do tempo necessário para preparação da lâmina (10 s), promovendo assim valores nulos ou próximos de zero quando o tempo de movimentação espermático é inferior ao intervalo desde a ativação espermática até a visualização dos espermatozóides no microscópio ótico.

O DMSO é considerado o melhor crioprotetor para peixes de água doce (Leung 1991) tendo proporcionado os melhores resultados em vários trabalhos com peixes nativos brasileiros de água doce (Viveiros \& Godinho 2009). No entanto, um estudo que considera o DMSO ineficiente como crioprotetor para a sêmen congelado de tambaqui (Menezes et al. (2008), foi baseado no uso de somente um reprodutor, sem descrição da concentração dos crioprotetores, da solução base utilizada, e do número de espermatozóides por ovo, o que dificulta a repetição de sua metodologia. Além disto, este mesmo estudo não avaliou as variáveis viabilidade celular, integridade da membrana e do DNA espermático, funcionalidade mitocondrial, taxa de fertilização e de eclosão com o DMSO.

$\mathrm{O}$ diluente e o protocolo de congelamento testados no presente estudo viabilizam o emprego desta ferramenta para programas de melhoramento animal ou formação de banco de germoplasma de $C$. macropomum, pois uma alta produtividade não é necessária nestas condições. Por outro lado, para uso em condições comerciais, são necessários trabalhos futuros avaliando diluentes, crioprotetores e protocolos de congelamento e descongelamento em sêmen de $C$. macropomum.

\section{CONCLUSÃO}

Considerando os resultados in vivo e in vitro, nas condições experimentais relatadas, o DMSO na concentração de $10 \%$ foi associado à melhor manutenção da qualidade de sêmen criopreservado de Tambaqui.

\section{AGRADECIMENTOS}

Este estudo foi patrocinado pela CAPES e CNPq. Os autores agradecem aos proprietários da Piscicultura Boa Esperança (Pimenta Bueno, RO, Brasil) por suas valiosas contribuições.

\section{REFERÊNCIAS}

BENCHARIF, D, L AMIRAT, O PASCAL, M ANTON, E SCHMITT, $S$ DESHERCES, G DELHOMME, M-L LANGLOIS, $P$ BARRIÈRE, M LARRAT \& D TAINTURIER, 2010. The Advantages of Combining Low-Density Lipoproteins with Glutamine for Cryopreservation of Canine Semen. Reprod. Dom. Anim., 45: 189-200.

BILLARD, R, J COSSON \& LW CRIM. 1995. Broodstock management and seed quality-General considerations. In: BROMAGE, N \& RJ ROBERTS. (Eds.). Broodstock management and egg larval quality, Oxford: Blackwell Science. 1-24.

CAROLSFELD, J, HP GODINHO, E ZANIBONI FILHO \& BJ HARVEY. 2003. Cryopreservation of sperm in Brazilian migratory fish conservation. J. Fish Biol., 63: 472-489.

CHELLAPA, S, NT CHELLAPA, WT BARBOSA, FA HUNTIGORD \& MCM BEVERIDGE. 1995. Growth and production of the Amazonian tambaqui in fixed cages under different feeding regimes. Aquacult. Intern., 3: 11-21.

COSER, AM, H GODINHO \& DM RIBEIRO. 1984. Cryogenic preservation of spermatozoa from Prochilodus scrofa and Salminus maxillosus. Aquacult., 37: 387-390.

CRUZ-CASALLAS, PE, SC PARDO-CARRASCO, JA ARIASCASTELLANOS, PE LOMBO-CASTELLANOS, DA LOMBORODRÍGUEZ \& JE PARDO-MARIÑO. 2004. Cryopreservation of Yamú Brycon siebenthalae milt. J. World Aquacult. Soc., 35: 529-535.

DEGRAAF, JD \& DL BERLINSKY. 2004. Cryogenic and refrigerated storage of rainbow smelt Osmerus mordax spermatozoa. J. World Aquacult. Soc., 35: 209-216.

FAO, Fishery and Aquaculture Statistics - Aquaculture production. 2008. Food and Agriculture Organization of the United Nations. 220p.

FARIAS, JO \& JF NUNES. 1999. Avaliação in vitro e in vivo do sêmen de tambaqui (Colossoma macroporum) conservado a temperatura ambiente e criopreservado em água de coco. Ver. Cient. Prod. Anim., 44-58. 
FELIZARDO, VO, RA MELLO, LDS MURGAS, ES ANDRADE, MM DRUMOND \& PV ROSA. 2010. Effect of cryopreservant combinations on the motility and morphology of curimba (Prochilodus lineatus) sperm. Anim. Reprod. Sci., 122: 259-263

FROESE, R. \& PAULY, D. 2009. Fish Base. Disponível em: www.fishbase.org, Acesso em: 29/04/2011.

HAMMERSTEDT, RH \& JK GRAHAM. 1992. Cryopreservation of poultry sperm: the enigma of glycerol. Cryobiology, 29: 26-38.

HARRISON, RAP \& SE VICKERS. 1990. Use of fluorescent probes to assess membrane integrity in mammalian spermatozoa. J. Reprod. Fert., 88: 343-352.

HE, S \& LC WOODS. 2004. Efects of dimethyl sulfoxide and glycine on cryopreservation induced damage of plasma membrane and mitochondria to striped bass (Morone saxatilis) sperm. Cryobiology, 48: 254-262.

HOLT, WV. 2000. Basic aspects of frozen storage of semen. Anim. Reprod. Sci., 62: 3-22.

HU, J, Q LI, Z JIANG \& W LI. 2008. Effects of different extenders on DNA integrity of boar spermatozoa following freezing-thawing. Crybiology, 57: 257-262.

HU, J, Q LI, Z JIANG, H YANG, S ZHANG \& H ZHAO. 2009. The Cryoprotective Effect of Trehalose Supplementation on Boar Spermatozoa Quality. Reprod. Dom. Anim., 44: 571-575.

KODERLE, M, C AURICH \& S SCHAFER-SOMI 2009. The influence of cryopreservation and seminal plasma on the chromatin structure of dog spermatozoa. Theriogenology. 72: 1215-1220.

LEUNG, LKP. Principles of biological cryopreservation. In: JAMIESON, GM. (Ed.). 1991. Fish evolution and systematics: evidence from spermatozoa. Cambridge: University Press, $244 \mathrm{p}$.

MARIA, AN, HC AZEVEDO, JP SANTOS \& PCF CARNEIRO. 2011. Hormonal induction and semen characteristics of tambaqui Colossoma macropomum. Zigote,5:1-5.

MELO FCSA \& HP GODINHO. 2006 A protocol for cryopreservation of spermatozoa of the fish Brycon orthotaenia. Anim. Reprod., 3: 380-385.

MENEZES, JTB, LJ QUEIROS, CRC DORIA \& JB MENEZES JR. 2008. Avaliação espermática pos-descongelamento em tambaqui, Colossoma Macroporum (Cuvier, 1818). Acta Amaz., 38: 365-368.

PURSEL, VG \& LA JOHNSON. 1975. Freezing of boar spermatozoa: Fertilizing capacity with concentrated semen and a new thawing procedure. J. Anim. Sci., 40: 99-102.

SALAMON, S \& WM MAXWELL. 2000. Storage of ram semen. Anim. Reprod. Sci., 62: 77-111.

SANSONE, G, A FABBROCINI, S IEROPOLI, AL LANGELLOTTI, $M$ OCCIDENTE \& D MATASSINO. 2002. Effects of extender composition, cooling rate, and freezing on the motility of sea bass (Dicentrarchus labrax L.) spermatozoa after thawing. Cryobiology, 44: 229-239.

STATISTIX ${ }^{\circledR}$ 9.0. 2008. Statistix for Windows User's manual. Tallahas-see: Analytical software.

STREIT JR, DP, C BENITES, GV MORAES, RP RIBEIRO, ES SAKAGUTI \& RF CALDIERI. 2006. Sêmen de pacu (Piaractus mesopotamicus) criopreservado com diluentes utilizados para sêmen de suínos. Ciênc. Anim. Bras., 7: 289-297.

SUQUET, M, C DREANNO, C FAUVEL, J COSSON \& R BILLARD. 2000. Cryopreservation of sperm in marine fish. Aquacult. Res., 31: 231-243.

TAITSON, PF, E CHAMI \& HP GODINHO. 2008. Gene banking of the neotropical fish Leporinus obtusidens (Valenciennes, 1836): A protocol to freeze its sperm in the field. Anim. Reprod. Sci., 105: 283-291.

VELASCO-SANTAMARIA, YM, VM MEDINA-ROBLES \& PE CRUZ-CASALLAS. 2006. Cryopreservation of yamú (Brycon amazonicus) sperm for large scale fertilization. Aquacult., 256: 264-271.

VIVEIROS ATM \& HP GODINHO. 2009. Sperm quality and cryopreservation of Brazilian freshwater fish species: a review. Fish Physiol. Biochem, 35: 137-150.

Submetido $-21 / 12 / 2011$

Aceito $-06 / 03 / 2012$ 
